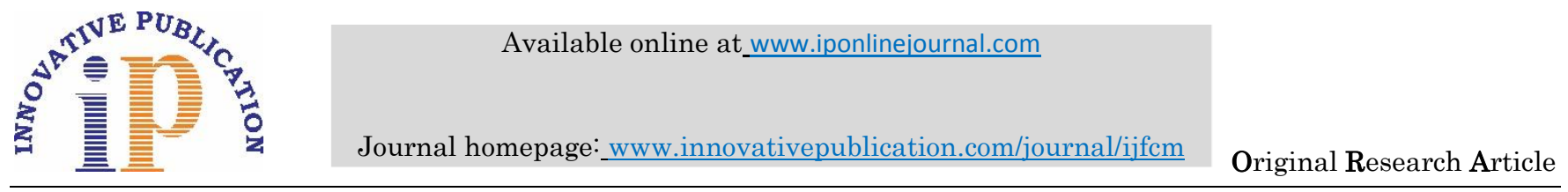

\title{
Prevalence of ocular morbidity among rural elderly of Belagavi
}

\author{
Preet Khona ${ }^{*}$, Chandra Metgud ${ }^{2}$
}

${ }^{\mathbf{1}}$ Assistant Professor, ${ }^{\mathbf{2}}$ Professor, Dept. of Community Medicine, Gadag Institute of Medical Sciences, Gadag, Karnataka, ${ }^{\mathbf{2} J a w a h a r l a l}$ Nehru Medical College, KAHER, Belagavi, Karnataka, India

\begin{abstract}
Introduction: Blindness and visual impairment by its sheer magnitude forms an enormous problem, not only in human suffering, but also in terms of economical loss and social burden. Globally, 285 million people are visually impaired. Among them, the preventable causes are as high as $80 \%$ and the main burden is carried by developing countries.

Materials and Methods: The present community based cross sectional study was conducted among individuals aged 60 years and above residing in the area covered under Vantamuri Primary Health Centre, Belagavi from $1^{\text {st }}$ January to $31^{\text {st }}$ December 2016 . Data was collected from the study subject regarding socio-demographic variables and personal history. Detailed ocular examination was carried out, which included external eye examination using torch, visual acuity examination, confrontation test and fundus examination using ophthalmoscope.

Results: The prevalence of ocular morbidities among elderly in rural area was $60.64 \%$. Mean number of ocular morbidities per person was $1.78+1.05$. Prevalence of visual impairment and blindness among elderly was $28.07 \%$ and $2.90 \%$ respectively. Major causes for ocular morbidities noted in our study were cataract, refractive error, retinopathies and glaucoma.

Conclusion: The present cross sectional study, reported a higher prevalence of ocular morbidities among elderly in rural area. Ocular morbidity favoured people with higher age, female sex and illiterates.
\end{abstract}

Keywords: Elderly population, Ocular morbidity, Rural area.

\section{Introduction}

Among the senses provided by God, sense of sight is supreme. Vision helps us understand what is, rather than on what should be. Loss of sight of a person should not remain just a statistics but a personal tragedy, not only for the individual concerned, but for all of us who claim to be concerned. $^{1}$

Globally, 285 million people are visually impaired, of whom 246 million have low vision, 39 million are blind. About $90 \%$ of the world's visually impaired live in lowincome settings. ${ }^{2}$ India has been labelled as an ageing nation with $8.6 \%$ of its population being more than 60 years old. In absolute terms the elderly population in India accounted for nearly 104 million in 2011. ${ }^{3}$ India has 6.7 million blind people and the estimated national prevalence of blindness in general population is $1 \%$. Of the blind people, $82 \%$ are above the age of 50 years. ${ }^{4}$

In India, of the total elderly population, two-thirds live in villages. Ocular morbidity is more common in rural areas, female gender, and the poor. Ocular morbidities if untreated reduce quality of life and economic productivity. The major reasons for the high prevalence of ocular morbidity in India may be increasing life expectancy, significantly more people aged above 40 years, poor access to eye care facilities in rural areas, misconceptions about cataract surgery, compromised water quality and environmental conditions, and lack of effective eye health education program. 5
The preventable causes are as high as 80 percent of the total global burden and are mainly seen in developing countries. The eye morbidity is multi-factorial; main causes being infections, poor nutrition and certain socio-cultural factors. Poor hygiene, sanitation and the climatic conditions can further aggravate the eye problems. ${ }^{6}$

In developing countries, data regarding the prevalence of ocular morbidities among elderly in rural areas is scarce. With introduction of universal eye health: a global action plan 2014-2019, dealing with reduction in avoidable blindness across the world, this study would help in enlightening the present scenario in this region. With this background, the present study was conducted among elderly in rural area of Belagavi to know the extent of ocular morbidities.

\section{Materials and Methods}

The present community based cross sectional study was conducted among individuals aged 60 years and above residing in the area covered under Vantamuri Primary Health Centre, Belagavi from $1^{\text {st }}$ January to $31^{\text {st }}$ December 2016. A sample size of 620 was calculated and obtained by population proportionate sampling from five subcentres under Vantamuri Primary Health Centre. The voters list of each subcentre was obtained. Sampling frame was prepared by sorting out individuals aged 60 years and above. Study participants were further chosen by using Random number table.

\footnotetext{
*Corresponding Author: Preet Khona, Dept. of Community Medicine, Gadag Institute of Medical Sciences, Gadag, Karnataka, India Email: preetkhona@gmail.com

http://doi.org/10.18231/J.IJFCM.2019.036
} 
The elderly persons in the study population were interviewed at their homes. All the subjects were informed about the purpose of the study and after obtaining informed consent they were interviewed using pre-structured and pretested proforma. Data regarding socio-demographic variables, alcohol and tobacco consumption, indoor air pollution and previous history of diabetes, hypertension, or any ocular surgeries was collected.

The participant underwent external eye examination using torch light to identify any diseases of eye lids, lacrimal apparatus, conjunctiva, cornea and nystagmus. Each person was tested for visual acuity using Snellen's E charts (separately for distant and near vision).A person was labelled blind when the visual acuity was less than counting fingers at three metres in the better eye. Confrontation test was performed to detect any gross diminution of field of vision. Fundoscopy was carried out by direct ophthalmoscope with dilatation of pupils whenever a person was found to have the visual acuity less than $6 / 9$ or patient was a known case of hypertension or diabetes mellitus. Refractive error was crudely estimated from lens power readings of the ophthalmoscope. Any lenticular opacity visible with distant direct ophthalmoscope against a red reflex was labelled as cataract after external eye examination. Lacrimal sac disorders were diagnosed based on clinical signs and symptoms. Glaucoma suspects and other doubtful cases were referred for final diagnosis to ophthalmologist, KLE hospital, Belagavi.

The data was tabulated and analyzed using Statistical Package for Social Sciences (SPSS), version 24.0 and the prevalence of each risk factor was expressed in terms of percentages. Statistical analysis was done using Pearson's Chi- Square test to find out the association between ocular morbidities and risk factors. A probability value ( $p$ value) of less than 0.05 was considered as significant.

\section{Results}

A total 620 participants aged 60 years and above participated in the study, among which 367 (59.19\%) were female and $253(40.81 \%)$ were male. The mean \pm SD age of the study participant was $65.26+6.04$ years. In the present study, among 253 male and 367 female participant, 121 $(47.83 \%)$ and $176(47.96 \%)$ were illiterate respectively. Nearly $120(19.35 \%)$ participant belonged to Class I of modified B. G. Prasad classification, 38 (6.13\%) to Class II, $180(29.04 \%)$ to Class III, 221 (35.64\%) to Class IV and 61 $(9.84 \%)$ to Class V. (Table 1$)$

Table 1: Socio demographic profile of study participants

\begin{tabular}{|c|c|c|c|c|c|}
\hline Age (in years) & $\begin{array}{c}\text { Male } \\
\mathbf{n}(\boldsymbol{\%})\end{array}$ & $\begin{array}{c}\text { Female } \\
\mathbf{n}(\boldsymbol{\%})\end{array}$ & Literacy status & $\begin{array}{c}\text { MALE } \\
\mathbf{n}(\boldsymbol{\%})\end{array}$ & $\begin{array}{c}\text { Female } \\
\mathbf{n}(\boldsymbol{\%})\end{array}$ \\
\hline $\mathbf{6 0}-\mathbf{6 5}$ & $157(62.06)$ & $240(65.39)$ & Illiterate & $121(47.83)$ & $176(47.96)$ \\
\hline $\mathbf{6 6}-\mathbf{7 0}$ & $55(21.74)$ & $76(20.71)$ & Primary school & $85(33.60)$ & $143(38.96)$ \\
\hline $\mathbf{7 1}-\mathbf{7 5}$ & $28(11.07)$ & $30(8.17)$ & Secondary school & $29(11.46)$ & $25(6.81)$ \\
\hline $\mathbf{7 6}-\mathbf{8 0}$ & $04(1.58)$ & $04(1.09)$ & Puc & $13(5.14)$ & $20(5.45)$ \\
\hline$>\mathbf{8 0}$ & $09(3.55)$ & $17(4.64)$ & Degree & $05(1.97)$ & $03(0.82)$ \\
\hline Total & $\mathbf{2 5 3 ( 1 0 0 )}$ & $\mathbf{3 6 7}(\mathbf{1 0 0})$ & Total & $\mathbf{2 5 3 ( 1 0 0 )}$ & $\mathbf{3 6 7}(\mathbf{1 0 0})$ \\
\hline Socio economic status & $\mathbf{N u m b e r}(\mathbf{\%})$ & Religion & Number (\%) \\
\hline Class i & $120(19.35)$ & HINDU & $579(93.38)$ \\
\hline Class ii & $38(6.13)$ & MUSLIM & $35(5.65)$ \\
\hline Class iii & $180(29.04)$ & JAIN & $06(0.97)$ \\
\hline Class iv & $221(35.64)$ & TOTAL & $\mathbf{6 2 0}(\mathbf{1 0 0})$ \\
\hline Class v & \multicolumn{2}{|c|}{$61(9.84)$} & & \\
\hline Total & $\mathbf{6 2 0}(\mathbf{1 0 0})$ & & \\
\hline
\end{tabular}

The prevalence of ocular morbidity in the present study was $60.64 \%$. Out of 376 study participant who had morbidity, 164(43.62\%) were male and 212(56.38\%) were female, 148(39.36\%) had one ocular morbidity, 172(45.74\%) had two, 46 $(12.24 \%)$ had three and $10(2.66 \%)$ had four morbidities. The mean number of ocular morbidity per person was $1.78+1.05$. The mean number of ocular morbidity in male and female study participant was $1.75+0.66$ and $1.81+0.82$ respectively.

The total number of ocular morbidities observed across 376 study participant was 670 . The common ocular morbidity noted were 249 (37.16\%) had cataract, 230(34.33\%) had refractive error, 45(6.71\%) had diabetic retinopathy, 41(6.12\%) had pseudophakia / aphakia, 34(5.07\%) had hypertensive retinopathy, $24(3.58 \%)$ had pterygium, 16(2.39\%) had acute conjunctivitis, $10(1.49 \%)$ had glaucoma, $7(1.04 \%)$ had stye, $5(0.75 \%)$ had nystagmus, $5(0.75 \%)$ had chalazion and $4(0.60 \%)$ had dacrocystitis.

In our study, the prevalence rate of ocular morbidity was $55.66 \%, 69.46 \%$ and $61.54 \%$ among 60 to 65 years, 66 to 70 years and above age 80 years respectively. As the age increased the prevalence rate of ocular morbidity also increased. $\left(x^{2}=\right.$ $12.46, \mathrm{p}=0.01)$ Though male preponderance was seen, sex of the study participant was not significantly associated with prevalence of ocular morbidity. Although ocular morbidities were higher in participants belonging to Muslim and Jain religion, it was not significantly associated with prevalence of ocular morbidity. Literacy rate was significantly associated $\left(\varkappa^{2}\right.$ 
$=11.98, \mathrm{df}=4, \mathrm{p}=0.02$ ); whereas socioeconomic status and occupation of study participant was were not associated with prevalence of ocular morbidity. (Table 2 and 3)

Table 2: Association between age and literacy status of study participant and ocular morbidity

\begin{tabular}{|c|c|c|c|c|}
\hline \multicolumn{4}{|c|}{ Ocular Morbidity } & \multirow{8}{*}{$\begin{array}{c}x^{2}=12.46, \text { df }= \\
4, p=0.01\end{array}$} \\
\hline $\begin{array}{c}\text { Age } \\
\text { (in years) }\end{array}$ & $\begin{array}{c}\text { Present } \\
\mathbf{N}(\%)\end{array}$ & $\begin{array}{l}\text { Absent } \\
\text { N (\%) }\end{array}$ & Total n(\%) & \\
\hline $60-65$ & $221(55.66)$ & $176(44.34)$ & $397(100)$ & \\
\hline $66-70$ & $91(69.46)$ & $40(30.54)$ & $131(100)$ & \\
\hline $71-75$ & $42(72.41)$ & $16(27.59)$ & $58(100)$ & \\
\hline $76-80$ & $06(75.00)$ & $02(25.00)$ & $08(100)$ & \\
\hline$>80$ & $16(61.54)$ & $10(38.46)$ & $26(100)$ & \\
\hline Total & $376(60.64)$ & 244 (39.36) & $620(100)$ & \\
\hline Literacy status & $\begin{array}{c}\text { Present } \\
\text { N }(\%)\end{array}$ & $\begin{array}{c}\text { Absent } \\
\text { N (\%) }\end{array}$ & $\begin{array}{l}\text { Total } \\
\text { N }(\%)\end{array}$ & \multirow[t]{7}{*}{$\begin{array}{c}x^{2}=11.98, \text { df }= \\
4, p=0.02\end{array}$} \\
\hline Illiterate & $200(67.34 \%)$ & $97(32.66 \%)$ & $297(100)$ & \\
\hline Primary & $127(55.70 \%)$ & $101(44.30 \%)$ & $228(100)$ & \\
\hline Secondary & $28(51.85 \%)$ & $26(48.15 \%)$ & $54(100)$ & \\
\hline Puc & $18(54.54 \%)$ & $15(45.46 \%)$ & $33(100)$ & \\
\hline Degree & $03(37.5 \%)$ & $05(63.5 \%)$ & $8(100)$ & \\
\hline Total & $376(60.64)$ & $244(39.36)$ & $620(100)$ & \\
\hline
\end{tabular}

Table 3: Association between sex, religion and occupation of study participant and ocular morbidity

\begin{tabular}{|c|c|c|c|c|}
\hline \multicolumn{4}{|c|}{ Ocular Morbidity } & \multirow{5}{*}{$\begin{array}{l}\mathcal{X}^{2}=3.12, \mathrm{df} \\
=1, \mathrm{p}=0.07\end{array}$} \\
\hline Sex & $\begin{array}{c}\text { Present } \\
\mathbf{N}(\%)\end{array}$ & $\begin{array}{l}\text { Absent } \\
\mathbf{N}(\%)\end{array}$ & $\begin{array}{r}\text { Total } \\
\mathbf{N}(\%)\end{array}$ & \\
\hline Male & $164(64.82)$ & $89(35.18)$ & $253(100)$ & \\
\hline Female & $212(57.77)$ & $155(42.23)$ & $367(100)$ & \\
\hline Total & $376(60.64)$ & $244(39.36)$ & $620(100)$ & \\
\hline Religion & $\begin{array}{l}\text { Present } \\
\text { N }(\%)\end{array}$ & $\begin{array}{l}\text { Absent } \\
\text { N (\%) }\end{array}$ & $\begin{array}{l}\text { Total } \\
\text { N }(\%)\end{array}$ & \multirow[t]{5}{*}{$\begin{array}{l}x^{2}=5.65, \mathrm{df} \\
=2, p=0.06\end{array}$} \\
\hline Hindu & $344(59.41 \%)$ & $235(40.59 \%)$ & $579(100)$ & \\
\hline Muslim & $27(77.14 \%)$ & $08(22.86 \%)$ & $35(100)$ & \\
\hline Jain & $05(83.33 \%)$ & $01(16.67 \%)$ & $06(100)$ & \\
\hline Total & $376(60.64)$ & 244 (39.36) & $620(100)$ & \\
\hline Occupation & $\begin{array}{c}\text { Present } \\
\text { N }(\%)\end{array}$ & $\begin{array}{c}\text { Absent } \\
\mathbf{N}(\%)\end{array}$ & $\begin{array}{c}\text { Total } \\
\mathbf{N}(\%)\end{array}$ & \multirow[t]{6}{*}{$\begin{array}{l}x^{2}=5.46, \mathrm{df} \\
=3, p=0.14\end{array}$} \\
\hline Retired & $54(72.98)$ & $20(27.02)$ & $74(100)$ & \\
\hline Farmer & $129(59.72)$ & $87(40.28)$ & $216(100)$ & \\
\hline Industry worker & 45 (57.69) & $33(42.31)$ & $78(100)$ & \\
\hline Housewife & $148(58.73)$ & $104(41.27)$ & $252(100)$ & \\
\hline Total & $376(60.64)$ & $244(39.36)$ & $620(100)$ & \\
\hline
\end{tabular}

\section{Discussion}

A total of 620 participants were examined in the study. The prevalence of ocular morbidity in our study was $60.64 \%$. Out of 376 study participant, who had morbidity, $43.62 \%$ were male and $56.38 \%$ were female. In various studies across India, prevalence of ocular morbidity varied from 40 to $90 \%$. A cross sectional study conducted in Jasra and Saidabad blocks of Allahabad, reported $40.92 \%$ ocular morbidity among elderly. A higher morbidity was seen among female $(53.60 \%){ }^{7}$ A comparative study among elderly of urban and rural areas in Allahabad showed 66.5\% prevalence of ocular morbidity among rural elderly individual. ${ }^{8} \mathrm{~A}$ study conducted in Barabanki, revealed
$88.8 \%$ ocular morbidity among elderly population in rural area $^{9}$. Female gender $(59.20 \%)$ was more prone for ocular morbidity, which was seen in a study in Jasra and Saidabad blocks of Allahabad. ${ }^{?}$

A study conducted in Kanpur, stated that average ocular lesion per case was 1.24 and the range was between one to three.$^{10} \mathrm{~A}$ cross sectional study carried out in Wardha district of Maharashtra revealed ocular morbidity rate as 1.21 lesions per elderly person. ${ }^{11}$ Our study was conducted among elderly and the above mentioned studies were among general population so some differences were seen. In our 
study two ocular morbidities was commoner than one. The number of ocular lesions was more in female participant.

A study conducted in Bundelkhand, noted that the prevalence of cataract to be $41 \%$, aphakia $14.2 \%$, refractive error $43.4 \%$, glaucoma $3.7 \%$ and corneal opacity $3.3 \% .^{12}$ Another study conducted in Wardha district, revealed that refractive error $(85 \%)$ to be the most common ocular morbidity among elderly followed by cataract $(36.3 \%)$, dry eye $(12.7 \%)$, diabetic retinopathy $(8.9 \%)$ and glaucoma $(5.6 \%) .{ }^{13}$ The findings in our study were mostly similar to the observations seen in various studies with cataract topping the list followed by refractive error. As the age increased protein in the lens of eye starts fusing to form cataract, which might be the cause for higher prevalence of cataract.

As the age increased the prevalence rate of ocular morbidity also increased $\left(x^{2}=12.46, \mathrm{p}=0.01\right)$. This increase in prevalence rate as age increases can be due to various factors which include, weakening of their pupillary muscles leading to refractive error, coagulation of lens proteins leading to cataract, decrease in neurons as age increases leading to neural and retinal changes, association with other diseases like diabetes and hypertension leading to their complications, which cause ocular morbidity. People with better education tend to be more attentive and concerned about their health and hygiene, which decreases the risk of morbidity, which may be the reason for lower prevalence of ocular morbidity. A similar study conducted among rural elderly in Wardha district, showed significant association between various ocular morbidities with increasing age $(\mathrm{p}<0.05)$ and educational status $(\mathrm{p}<0.05) .{ }^{13} \mathrm{~A}$ study conducted among urban population of Meerut revealed that ocular morbidity was significantly higher $(\mathrm{p}<0.01)$ in female $(56.2 \%)$ than male $(49.1 \%){ }^{6}$

In our study there was no statistical significant difference, but except class V SES, decreasing trend was seen from lower to upper class, but no such trend was seen in relation to occupation. Though among Muslim, 77.14\% and among Jain, $83.33 \%$ had an ocular morbidity, religion was not significantly associated with prevalence of ocular morbidity. This may be mainly due to the Hindus predominance in the area which led to less study subjects of other religion.

\section{Conclusion}

The present cross sectional study, noted a prevalence rate of $60.64 \%$ ocular morbidity among elderly in rural area. Ocular morbidity favoured people with higher age, female sex and illiterates. Major causes for ocular morbidity included cataract, refractive error, retinopathies and glaucoma, all of which are preventable or treatable. Prevalence of ocular morbidities varied with age, sex, religion and literacy status of study participant.

Based on the findings of our study, the recommendations which can be implemented include, need for more comprehensive interventions targeting the identification of risk factors, development of screening procedures using simple diagnostic criteria which can be utilized for training the field workers, mobile health clinics equipped with all basic modern technologies can be the solution for curing the cases who are reluctant to seek care for their illness.

\section{Declarations}

Ethical approval: The study was approved by Institutional Ethical Committee of Jawaharlal Nehru Medical College, Belagavi. (MDC/DOME/377 dated: 18/11/2015)

\section{Source of Funding}

None.

\section{Conflict of interest}

None.

\section{References}

1. Thylefors B. Avoidable blindness. Bull World Health Organ 1999;77:453.

2. Global data on visual impairment 2010. World Health Organisation; 2010. Accessed on: $6^{\text {th }}$ July, 2017. Available from:http://www.who.int/blindness/GLOBALDATAFINALfor web.pdf?ua=1

3. Ministry of statistics and programme implementation. Elderly in India. Government of India; 2016. Accessed on: $2^{\text {nd }}$ August 2017. Available from: http://mospi.nic.in/sites/default/files/publication_reports/Elderl yinIndia_2016.pdf

4. Ministry of Health and Family Welfare, Government of India. National Programme for Control of Blindness. Accessed on: $15^{\text {th }}$ July 2017. Available at: http://npcb.nic.in/

5. Rajan, Irudaya S. Population ageing and health in India. Mumbai: Centre for Enquiry into Health and Allied Themes; 2006. Accessed on: $2^{\text {nd }}$ August 2017. Available at: www.cehat.org.

6. Agrawal D, Singh JV, Sharma MK, Mitthal S. Ocular morbidity pattern of an urban population of Meerut. Ind J Prev Soc Med 2011;42(1):75-8.

7. Singh A, Dwivedi S, Dabral SB, Bihari V, Rastogi AK, Kumar $\mathrm{D}$ et al. Ocular morbidity in the rural areas of Allahabad, India. Nepal J Ophthalmol 2012;4(7):49-53.

8. Verma V, Prakash S, Parveen K, Shaikh S, Mishra N. A comparative study of morbidity pattern in elderly of rural and urban areas of Allahabad district, Uttar Pradesh, India. Int J Community Med Public Health 2016;3:1152-6.

9. Kumar A, Srivastava AK, Mishra M, Srivastava VK. Prevalence of ocular morbidity in rural population of eastern Uttar Pradesh, India. Indian J Comm Health 2016;28(3):275-9.

10. Mehrotra S K, Maheshwari B B. Prevalence of ocular lesions in a rural community. Indian J Ophthalmol 1975;23:17-20.

11. Singh MM, Murthy GV, Venkatraman R, Rao SP, Nayar S. A study of ocular morbidity among elderly population in a rural area of central India. Indian J Ophthalmol 1997; 45:61-65.

12. Jitendrakumar, Sirohi N, Tiwari N. Ocular Morbidity Among Elderly Population in Rural Areas of Bundelkhand. IOSR J Dent Med Sci 2016;15(6)(VIII):5-10.

13. Pisudde PM, Taywade ML, Sushma K, Mehendale AM, Shukla AK. An Epidemiological Study of Common Ocular Morbidities among Elderly Population in the Wardha, District, Maharashtra, India. Epidemiology 2015;5:002.

How to cite this article: Khona $\mathrm{P}$, Metgud $\mathrm{C}$, Prevalence of ocular morbidity among rural elderly of Belagavi. Indian $J$ Forensic Community Med 2019;6(3):159-62. 